\title{
HUBUNGAN POLA ASUH ORANG TUA TERHADAP PERILAKU SEKSUAL REMAJA DI DESA NAULI KECAMATAN SIGUMPAR KABUPATEN TOBA
}

\author{
Munarni \\ Program Studi D-III Keperawatan, STIKes Arjuna \\ E-mail : arnysweet84@gmail.com
}

\begin{abstract}
Abstrak
Parenting greatly affects the role and function of the family. The influence of the family in the formation and development of children's personalities is very large because the family is the first social group where children can interact, where children learn, and declare themselves as social beings. The family can also provide the basis for the formation of behavior, character, morals, and education for children. This study aims to determine the relationship between parenting and adolescent sexual behavior in Nauli Village, Sigumpar District, Toba District. This study used a descriptive correlation research design . P opulation and the sample in this study were adolescents who live at home with their parents in the village of Nauli. Sampling with simple random sampling. The study was conducted in April 2020, and used a questionnaire consisting of demographic data, a parenting style questionnaire and a youth sexual behavior questionnaire. The research data were tested using the SPSS version 12.0 program using the analyze descriptive and displayed in categorical form. From the results of this study showed that the majority of respondents $(76.1 \%)$ have a democratic parenting, adolescent sexual behavior of the majority of respondents in the positive category $((95.5 \%)$. The analyst is statistics showed that no significant relationship between parenting parents on adolescent sexual behavior $\mathrm{p}$ value $=0.223$. Based on the results of the research obtained, it is recommended that further research related to the title of this study is suggested to examine other factors that influence adolescent sexual behavior and to use more respondents and research in several different places so that the results are more representative.
\end{abstract}

Keywords : Parenting Patterns, Adolescent Sexual Behavior

\begin{abstract}
Abstrak
Pola asuh sangat mempengaruhi peran dan fungsi keluarga. Pengaruh keluarga dalam pembentukan dan perkembangan kepribadian anak sangat besar karena keluarga merupakan kelompok sosial yang pertama dimana anak dapat berinteraksi, tempat anak belajar, dan menyatakan dirinya sebagai makhluk sosial. Keluarga juga dapat memberikan dasar pembentukan tingkah laku, watak, moral, dan pendidikan kepada anak. Penelitian ini bertujuan untuk mengetahui hubungan pola asuh orangtua terhadap perilaku seksual remaja di Desa Nauli Kec.Sigumpar Kab.Toba. Penelitian ini menggunakan desain penelitian korelasi deskriptif. Populasi dan sampel dalam penelitian ini adalah remaja yang tinggal serumah dengan orangtuanya di Desa Nauli. Pengambilan sampel dengan simple random sampling. Penelitian dilakukan pada bulan April 2020, dan menggunakan kuesioner yang terdiri dari data demografi, kuesioner pola asuh orangtua dan kuesioner perilaku seksual remaja. Data hasil penelitian di uji menggunakan program SPSS versi 12,0 dengan menggunakan deskriptif analyze dan ditampilkan dalam bentuk kategorik. Dari hasil penelitian ini diperoleh hasil bahwa mayoritas responden $(76,1 \%)$ memiliki pola asuh demokrasi, Perilaku seksual remaja mayoritas responden dalam kategori positif $((95,5 \%)$. Analisis statistik diperoleh bahwa hubungan yang tidak signifikan antara pola asuh orangtua terhadap perilaku seksual remaja nilai $p=0,223$. Berdasarkan hasil penelitian yang diperoleh, direkomendasikan untuk penelitian selanjutnya yang berkaitan dengan judul penelitian ini disarankan untuk meneliti faktor-faktor lain yang mempengaruhi perilaku seksual remaja dan menggunakan lebih banyak responden dan meneliti dibeberapa tempat yang berbeda agar hasilnya lebih representatif.
\end{abstract}

Kata Kunci : Pola Asuh Orang Tua, Perilaku Seksual Remaja 


\section{PENDAHULUAN}

Bentuk pola asuh orang tua terhadap anak merupakan interaksi antara anak dan orang tua selama mengadakan kegiatan pengasuhan, mendidik, membimbing, dan mendisiplinkan serta melindungi anak untuk mencapai kedewasaan sesuai dengan normanorrma yang berlaku di masyarakat (Shochib, 2000).

Pola asuh sangat mempengaruhi peran dan fungsi keluarga.Pengaruh keluarga dalam pembentukan dan perkembangan kepribadian anak sangat besar karena keluarga merupakan kelompok sosial yang pertama di mana anak dapat berinteraksi, tempat anak belajar, dan menyatakan dirinya sebagai makhluk sosial.Keluarga juga dapat memberikan dasar pembentukan tingkah laku, watak, moral, dan pendidikan kepada anak (Kartono, 2010).

Orang tua sering mengeluh karena tidak adanya rasa tanggung jawab, terutama sekali sulit mengharapkan agar orang tua mempunyai tanggung jawab dalam perilaku seksual anaknya. Jika orang tua tidak sanggup menjawab rasa ingin tahu anak tentang sikap seksualnya, maka orang tua itu merasa gagal. Orang tua tidak berhak menyalahkan si anak bila anak itu mengecewakan. Jadi ketika anak-anak mengajukan pertanyaan tentang masalah seks, pertanyaan itu seharusnya dijawab dengan sebenarnya dan diberi informasi tertulis yang benar, termasuk dengan gambar. Jadi orang tua harus selalu menekankan bahwa seks adalah fungsi alamiahtapi mengandung tanggung jawab kepada orang lain (Soelaeman, 1988).

Perilaku seksual ini lebih baik diketahui dari orang tuanya, dari pada si anak mendapatkannya dari pendapat atau khayalan sendiri, teman, buku-buku, atau pun film-film porno yang kini dijual bebas. Dari khayalan itu mereka dapat saja menyalah gunakan arti dan fungsi organ seksualnya. Dengan demikian salah satu yang mungkin bisa mengontrol perilaku seksual anak remaja adalah monitoring orang tua. Jadi orang tua mempunyai peranan penting karena yang pertama sekali remaja tumbuh di keluarganya sendiri. Artinya orang tua harus menyediakan waktu yang ekstra untuk memperhatikan anak remajanya terutama dalam perilaku seksual. (Dianawati, 2003).

Dari uraian tersebut, peneliti menarik kesimpulan bahwa perilaku seksual yang menyimpang yang terjadi pada remaja disebabkan karena kondisi pengasuhan dari keluarga khususnya orangtua dalam hal pengasuhan anak. Kesalahan pengasuhan ini dapat berupa pola asuh yang tidak tepat sehingga berdampak terhadap perilaku seksual remaja.Variabel perilaku seksual remaja meliputi kurangnya pemahaman yang disebabkan berbagai macam seperti adat istiadat, budaya, agama, dan kurangnya informasi dari sumber yang benar.Sehingga peneliti tertarik untuk meneliti dengan judul Hubungan Pola Asuh Orang tua terhadap Perilaku Remaja di Desa Nauli Kec.Sigumpar Kab. Toba tahun 2020.

Berdasarkan latar belakang tersebut yang menjadi perumusan masalah adalah: "Bagaimanakah Hubungan Pola Asuh Orang tua terhadap perilaku seksual remaja di Desa Nauli Kec.Sigumpar Kab.Toba tahun 2020"

\section{METODE PENELITIAN}

Dalam penelitian ini, menggunakan desain penelitian deskriptif korelasi yaitu untuk mengetahui hubungan yang terjadi pada sebuah fenomena dengan mengidentifikasi hubungan yang terjadi pada dua variabel (Suyanto \& Salamah, 2009). Penelitian ini dilakukan di Desa Nauli Kec.Sigumpar Kab.Toba. Penelitian dilakukan pada April 2020 sampai dengan Juni tahun 2020. Populasi pada penelitian ini adalah remaja di Desa Nauli Kec.Sigumpar Kab.Toba, selama bulan Januari sampai September 2020 yaitu sebanyak 114 orang remaja, dan jumlah sampel sebanyak 88 orang remaja. Teknik pengambilan sampel menggunakan pendekatan secara simplerandom sampling yaitu pengambilan sampel secara acak tanpa memperhatikan strata yang ada pada populasi tersebut. Dilakukan dengan cara membuat undian pada kertas-kertas kecil, yang telah ditulis nama- 
nama remaja pada satu kertas undian. Kemudian kertas undian diambil secara acak sebanyak 88 buah.

Didalam proses pengumpulan data, pada tahap awal peneliti mengajukan permohonan izin pelaksanaan penelitian pada Ketua STIKes Arjuna, kemudian permohonan izin yang diperoleh dikirim ke tempat penelitian di Desa Nauli Kec.Sigumpar Kab.Toba. Setelah mendapat izin dari Kepala Desa Nauli, peneliti melakukan pengumpulan data penelitian. Peneliti menentukan responden sesuai dengan kriteria yang dibuat sebelumnya. Peneliti menemukan calon responden yang memenuhi kriteria cukup banyak maka peneliti memilih calon responden secara acak. Setelah mendapat calon responden, selanjutnya peneliti menjumpai responden dari rumah ke rumah dan di bantu Bapak Kepala Desa dan kebanyakan responden dijumpai pada siang dan malam hari, setelah itu peneliti menjelaskan tujuan dan manfaat penelitian serta proses pengisian kuesioner. Kemudian calon responden yang bersedia diminta untuk menandatangani surat persetujuan sebagai responden dalam penelitian ini. Setelah itu responden diminta mengisi kuesioner yang diberikan oleh peneliti. Responden diberi kesempatan untuk bertanya selama pengisian kuesioner, bila ada yang tidak dimengerti sehubungan dengan pertanyaan yang ada dalam kuesioner. Setelah semua responden mengisi kuesioner tersebut, maka seluruh data dikumpulkan untuk dianalisa.

Analisis data yang dipakai ada dua, yaitu: 1) Univariat, data dianalisis disajikan dalam bentuk tabel distribusi frekuensi dan persentase. 2) Bivariat, hubungan pola asuh orangtua terhadap perilaku remaja dianalisa dengan menguji hipotesi penelitian, kemudian ditarik kesimpulan dari hasil penelitian. Hipotesa diuji dengan menggunakan teknik analisis Chi-square. Teknik analisis korelasi ini digunakan untuk mencari koefisien korelasi atau kekuatan hubungan.

\section{HASIL PENELITIAN}

\section{Karakteristik Responden}

Karakteristik responden dapat dilihat pada tabel 1 yang terdiri atas usia remaja, jenis kelamin, agama, suku, dan tingkat pendidikan.

Tabel 1. Distribusi Frekuensi dan Persentase Karakteristik Responden

\begin{tabular}{lcc}
\hline Karakteristik & Frekuensi & Persentase \\
\cline { 2 - 3 } Responden & $\mathbf{n}$ & $\mathbf{\%}$ \\
\hline Umur & 32 & 36.4 \\
$12-13$ & 21 & 23.8 \\
$14-16$ & 35 & 39.8 \\
$17-20$ & $\mathbf{8 8}$ & $\mathbf{1 0 0}$ \\
\hline \multicolumn{1}{c}{ Total } & & \\
\hline Jenis Kelamin & 43 & 48.9 \\
Laki-laki & 45 & 51.1 \\
Perempuan & $\mathbf{8 8}$ & $\mathbf{1 0 0}$ \\
\hline \multicolumn{1}{c}{ Total } & & \\
\hline Agama & 24 & 27.3 \\
Islam & 46 & 52.3 \\
Protestan & 18 & 20.4 \\
Katolik & $\mathbf{8 8}$ & $\mathbf{1 0 0}$ \\
\hline \multicolumn{1}{c}{ Total } & & \\
\hline Suku & 41 & 46.7 \\
Batak Karo & 36 & 40.8 \\
Batak Toba & 7 & 8.0 \\
Jawa & 4 & 4.5 \\
Batak & & \\
Simalungun & $\mathbf{8 8}$ & $\mathbf{1 0 0}$ \\
\hline \multicolumn{1}{c}{ Total } & & \\
\hline Tingkat & & \\
Pendidikan & & \\
SMP & & \\
SMA & & \\
\hline$\quad$ Total & & \\
\hline
\end{tabular}

\section{Pola Asuh Orang tua di Desa Nauli Kec.Sigumpar Kab.Toba}

Data yang terkumpul menunjukkan bahwa mayoritas pola asuh orang tua responden adalah demokrasi $(76,1 \%)$.

Tabel 2. Pola Asuh Orang Tua di Desa Nauli Kec.Sigumpar Kab.Toba

\begin{tabular}{lcc}
\hline \multirow{2}{*}{ Pola asuh } & Frekuensi & Persentase \\
\cline { 2 - 3 } & $\mathbf{n}$ & $\mathbf{\%}$ \\
\hline Otoriter & 23 & 26,1 \\
Demokrasi & 65 & 73,9 \\
\hline Total & $\mathbf{8 8}$ & $\mathbf{1 0 0}$ \\
\hline
\end{tabular}




\section{Perilaku Seksual Remaja di Desa Nauli Kec.Sigumpar.Kab.Toba}

Data yang terkumpul menunjukkan bahwa mayoritas perilaku seksual remaja adalah berperilaku positif $(95,5 \%)$.

Tabel 3. Perilaku Seksual Remaja di Desa Nauli Kec.Sigumpar Kab.Toba

\begin{tabular}{lcc}
\hline Perilaku Seksual & Frekuensi & Persentase \\
\cline { 2 - 3 } & $\mathbf{n}$ & $\mathbf{\%}$ \\
\hline Positif & 84 & 95,5 \\
Negatif & 4 & 4,5 \\
\hline Total & $\mathbf{8 8}$ & $\mathbf{1 0 0}$ \\
\hline
\end{tabular}

4. Hubungan Pola Asuh Orang tua Otoriter terhadap Perilaku Seksual Remaja di Desa Nauli Kec.Sigumpar Kab.Toba

Analisis hubungan pola asuh orang tua terhadap perilaku seksual remaja diukur dengan menggunakan uji chi-square. Dari hasil analisis data didapat $p=0,569$ ( $\alpha=$ 0,05 ) yang berarti Ho gagal ditolak, artinya bahwa tidak terdapat hubungan yang bermakna antara pola asuh orangtua dengan perilaku seksual remaja di Desa Nauli Kec.Sigumpar Kab.Toba.

Tabel 4. Hubungan Pola Asuh Orang Tua terhadap Perilaku Seksual Remaja di Desa Nauli Kec.Sigumpar Kab.Toba

\begin{tabular}{lccccccc}
\hline $\begin{array}{l}\text { Pola Asuh } \\
\text { Orangtua }\end{array}$ & $\begin{array}{l}\text { Perilaku } \\
\text { remaja } \\
\text { positif }\end{array}$ & \multicolumn{4}{l}{$\begin{array}{l}\text { Perilaku } \\
\text { remaja } \\
\text { negatif }\end{array}$} & Jumlah & p \\
\cline { 2 - 7 } & $\mathbf{n}$ & $\mathbf{\%}$ & $\mathbf{n}$ & $\mathbf{\%}$ & $\mathbf{n}$ & $\mathbf{\%}$ & \\
\hline Otoriter & 23 & 26,1 & 0 & 0 & 23 & 26,1 & \\
\hline Demokrasi & 61 & 69,3 & 4 & 4,5 & 65 & 73,9 & 0,569 \\
\hline Total & $\mathbf{8 4}$ & $\mathbf{9 5 , 4}$ & $\mathbf{4}$ & $\mathbf{4 , 5}$ & $\mathbf{8 8}$ & $\mathbf{1 0 0}$ & \\
\hline
\end{tabular}

\section{PEMBAHASAN}

\section{Pola Asuh Orang Tua di Desa Nauli Kec.Sigumpar Kab.Toba \\ Data hasil penelitian ini} menunjukkan bahwa mayoritas responden memiliki pola asuh orang tua demokrasi yaitu 67 responden $(76,1 \%)$. Hasil penelitian tersebut didukung oleh hasil penelitian yang dilakukan oleh Lestari Endang (2007) yang menunjukkan bahwa dari 144 responden, sebanyak 135 responden $(93,75 \%)$ yang memiliki pola asuh orang tua demokrasi. Hal ini menunjukkan bahwa pola asuh demokrasi banyak digunakan oleh orang tua.

Menurut Shocib dalam (yuniati, 2003), orang tua yang menerapkan pola asuh demokrasi banyak memberikan kesempatan kepada anak untuk berbuat keputusan secara bebas, berkomunikasi dengan lebih baik, mendukung anak untuk memiliki kebebasan sehingga anak mempunyai kepuasan, dan sedikit menggunakan hukuman badan untuk mengembangkan disiplin.

Menurut Astuti (2005), pola asuh demokrasi dapat mendorong anak untuk mandiri, tapi orang tua tetap menetapkan batas dan kontrol serta memiliki dampak positif yaitu anak-anak akan merasa bahagia, mempunyai kontrol diri dan rasa percaya dirinya terpupuk, bisa mengatasi stress, punya keinginan untuk berprestasi dan bisa berkomunikasi dengan baik. Orang tua yang menerapkan pola asuh demokratis akan berusaha mengajak anak agar terbiasa menerima konsekuensi secara logis dalam setiap tindakannya sehingga anak akan menghindari keburukan karena dia sendiri merasakan akibat perbuatan buruk itu, bukan karena desakan orang tuanya.

\section{Perilaku Seksual Remaja di Desa Nauli Kec.Sigumpar Kab.Toba}

Hasil penelitian mengenai perilaku seksual remaja di Desa Nauli Kec.Sigumpar Kab.Toba dari 84 responden $(95,5 \%)$ mayoritas berperilaku positif. Hasil penelitian mengenai perilaku seksual remaja didukung oleh hasil penelitian yang dilakukan oleh Lestari Endang (2007), bahwa dari 144 responden, 125 responden $(86,8 \%)$ yang memiliki perilaku remaja yang positif. Hasil penelitian ini juga didukung oleh hasil penelitian yang dilakukan oleh Elizabeth Estin (2009), dari 53 responden, 46 responden $(86,8 \%)$ memiliki perilaku seksual positif.

Menurut Sarwono (2007), perilaku seksual merupakan tingkah laku yang didorong oleh hasrat seksual, baik dengan lawan jenis maupun sesama jenis. Bentukbentik tingkah laku ini bisa bermacam- 
macam, mulai dari perasaan tetarik sampai tingkah laku berkencan, bercumbu, dan bersenggama.Sebagian dari tingkah laku itu memang tidak berdampak apa-apa, terutama jika tidak ada akibat fisik atau sosial yang dapat ditimbulkannya. Akan tetapi, pada sebagian perilaku seksual yang lain dampaknya bisa cukup serius, seperti perasaan bersalah, depresi, marah, ketegangan mental, dan kebingungan akan peran sosial.

\section{Hubungan Pola Asuh Orangtua Terhadap Perilaku Seksual Remaja di Desa Nauli Kec.Sigumpar Kab.Toba}

Pada penelitian ini pola asuh dibagi atas dua tipe yaitu otoriter dan demokrasi.Untuk menghubungkan kedua pola asuh diatas dengan perilaku seksual remaja peneliti menggunakan uji chi-square.

Dari analisis statistika diperoleh nilai significance ( $\mathrm{p}$ value) sebesar 0,569 sehingga lebih besar dari $(\alpha)=0,05$. Ini berarti Ho gagal ditolak sehingga dapat disimpulkan tidak ada hubungan pola asuh orangtua terhadap perilaku seksual remaja.

Hasil penelitian ini sesuai dengan hasil penelitian yang dilakukan oleh Lestari Endang (2007), bahwa dari analisis statistika diperoleh nilai signifikan( $\mathrm{p}$ value) sebesar 0,700 sehingga lebih besar dari nilai $(\alpha)=$ 0,05 . Hal ini menunjukkan Ho gagal ditolak sehingga disimpulkan tidak ada hubungan pola asuh orangtua terhadap perilaku seksual remaja.

Dari hasil penelitian di atas, berbading terbalik dengan hasil penelitian yang dilakukan oleh Elizabeth Estin (2009), bahwa dari analisis statistika diperoleh nilaisignifikan ( $\mathrm{p}$ value) sebesar 0,000 sehingga lebih kecil dari nilai $(\alpha)=0,05$. Hal ini berarti Ho ditolak sehingga dapat disimpulkan terdapat hubungan yang bermakna antara pola asuh orang tua terhadap perilaku seksual remaja.

Menurut pendapat Lauritsen (1994) bahwa pola asuh orang tua baik otoriter maupun demokrasi tidak ada hubungan yang signifikan terhadap perilaku seksual remaja.Karena seperti pola asuh otoriter yang diterapkan di kalangan keluarga yang artinya berdampak buruk pada remaja, ketika diteliti bahwa orang tua yang menerapkan pola asuh otoriter tidak berdampak apa-apa pada anak remajanya.Remaja tersebut juga tidak ada berpengaruh terhadap pergaulan bebas, yang berhubungan dengan perilaku seksual remaja.

Sebaliknya, orang tua yang menerapkan pola asuh demokratis didalam teori mengatakan berdampak lebih baik pada remaja, artinya remaja menjadi mandiri, anak akan merasa bahagia, mempunyai kontrol diri dan rasa percaya dirinya terpupuk, bisa mengatasi stress, punya keinginan untuk berprestasi dan bisa berkomunikasi dengan baik, tetapi dari hasil penelitian orang tua yang menerapkan pola asuh demokratis pada anak remaja, mengakibatkan remaja tersebut menjadi ketergantuan terhadap orangtuanya. Tidak bisa mengambil keputusan atau pun tindakan yang tepat untuk dirinya. Anak remaja tersebut karena banyak nasehat tentang perilaku-perilaku remaja yang menyimpang terhadap seksual akan lebih ingin mengetahui lebih jauh apa yang hal apa yang dijelaskan orang tuanya tersebut

\section{KESIMPULAN}

Berdasarkan hasil penelitian dapat diketahui bahwa mayoritas responden berusia antara 17 - 20 tahun (39,8\%), dengan jenis kelamin perempuan $(51,1 \%)$, agama Kristen Protestan (52,3\%), dengan suku Batak Karo $(46,7 \%)$, jenjang pendidikan SMA $(54,5 \%)$.

Pola asuh yang digunakan orang tua responden mayoritas memiliki pola asuh demokratis yaitu sebanyak 67 responden. Perilaku seksual remaja mayoritas berperilaku positif sebanyak 84 responden.

Hasil uji chi-square diperoleh nilai probabilitas $(\mathrm{p}=0,252)>0,05$ maka Ho gagal ditolak, sehingga tidak ada hubungan yang bermakna antara pola asuh orang tua dengan perilaku seksual remaja.

\section{SARAN}

1. Untuk Pelayanan Keperawatan

Dalam melaksanakan asuhan kebidanan, diharapkan bidan lebih meningkatkan mutu dan kualitas pelayanan kebidanan 
yang mencakup memberikan pendidikan kesehatan dan penyuluhan kepada remajaremaja dalam mencegah penyimpangan seksual yang tidak diinginkan seperti penyuluhan perilaku seksual apa yang sepantasnya dilakukan dan tidak dapat dilakukan oleh remaja. Tujuannya agar remaja dapat mengantisipasi dan memahami hal-hal yang dapat merugikan remaja itu sendiri.

2. Untuk Pendidikan Kebidanan

Dari hasil penelitian ini diharapkan dapat menjadi suatu cerminan agar remaja khususnya diinstitusi pendidikan lebih mengetahui perilaku-perilaku remaja yang menyimpang, untuk itu mahasiswa kebidanan, melalui pendidikan kebidanan terdorong untuk melakukan kegiatan pencegahan penyimpangan perilaku seksual remaja dalam kegiatan praktek kebidanan dan dapat mengaplikasikan ilmunya khususnya tentang kesehatan reproduksi pada remaja dimasyarakat.

3. Untuk Peneliti Keperawatan

Responden dalam penelitian ini adalah sebanyak 88 orang didesa Nauli Jumlah ini dirasakan peneliti belum cukup untuk mewakili remaja-remaja lainnya yang mengalami perilaku seksual remaja yang menyimpang.Oleh sebab itu, disarankan kepada peneliti selanjutnya untuk menggunakan lebih banyak responden dan meneliti dibeberapa tempat yang berbeda agar hasilnya lebih representatif.

\section{REFERENSI}

Abineno, J.L.Ch. (2002). Seksualitas dan pendidikan seksual. PT BPK Gunung Mulia.

Ariyanto. (2008). Penelitian perkumpulan keluarga berencana indonesia. Dari http://www.kompas.com/kompascetak/0205/10/iptek/rema33/htm

Azwar, S. (2000). Reliabilitas dan validitas. Yogyakarta : Pustaka Pelajar.

Bronckopp, D.Y, dan Hastings, M.T. (2000). Dasar-dasar riset keperawatan. Jakarta : EGC
Dianawati ajen. (2003). Pendidikan seks untuk remaja. Jakarta : PT.Kawan Pustaka

Endang, L. (2006). Tipe pola asuh orangtua terhadap moral remaja di smu negeri 1 medan. Medan : Universitas Sumatra Utara.

Elizabeth Estin. (2009). Hubungan monitoring parenteral dengan perilaku seksual remaja di kelurahan kebun sayur. Pematang Siantar : Politeknik Kesehatan Medan

Garliah, Lili. (2003). Peran pola asuh orangtua dengan penalaran moral dalam kepemimpinan transformasi remaja smu negeri 1 di Medan. PPS UNPAD. Disertasi. Bandung: Program Studi Psikologi Perkembangan

Gunarsa, S, D. (1993). Psikologi praktis : anak, remaja dan keluarga. Jakarta : PT. BPK.Gunung Mulia

Hidayat, A. (2007). Metode penelitian kebidanan teknik analisis data. Jakarta : Salemba Medika.

Hurlock, E, B. (1999). Psikologi perkembangan suatu pendekatan sepanjang rentang kehidupan. Edisi 5. Jakarta : Erlangga

Kartono, K. (2010). Kenakalan remaja. Jakarta : PT. Rajagravindo Persada

Notoatmodjo, S. (2005). Metodologi penelitian kesehatan. Jakarta :RinekaCipta

Nursalam.(2008). Konsep penerapan metodologi penelitian ilmu keperawatan. Jakarta : Salemba Medika

Sarwono W \& Sarlito. (2010). Psikologi remaja. Jakarta : PT. Rajagravindo Persada

Sastroasmoro, S. (2006). Dasar-dasar metodologi penelitian klinis. Jakarta : Sagung Seto

Shochib, m. (2000). Pola asuh orangtua. Jakarta : Rineka Cipta.

Soelaiman, MI. (1998). Moralitas, perilaku moral, dan perkembangan moral. Jakarta : Universitas Indonesia (UI Press) 
Cetak ISSN : 2620-5564

Online ISSN : 2655-1292

Suyanto, S. (2009). Riset kebidanan metodologi dan aplikasi. Jogjakarta : Mitra Cendekia.

Tarmudji, T. (2008). Hubungan pola asuh orangtua dengan agresivitas remaja. Dari http://www.depdiknas.go.id/ jurnal/37/hubungan-pola-asuhorangtua.htm. 